\title{
Headache Management with Occipital Nerve Blocks, Cervical Injections and Trigger Point Injections
}

\author{
Larry Mellick* and Neha Verma
}

Department of Emergency Medicine, Medical College of Georgia, Augusta, 1120 15th Street Georgia, 30912, USA

\begin{abstract}
In this article three different intramuscular injection procedures used to treat headache pain are reviewed. These procedures, occipital nerve blocks, cervical injections and trigger point injections, are described and the supporting literature is reviewed.
\end{abstract}

Keywords: Headache, cephalgia, cervical injections, trigger point, occipital nerve block, injections.

\section{INTRODUCTION}

The injection of anesthetics into the muscles of the head and neck is becoming increasingly accepted as a therapeutic modality for treating headache pain. While the most effective headache treatment for primary headaches is intravenous prochlorperazine (typically administered with diphenhydramine to counteract the common side effect of akathisia) [1-4], there are other therapeutic techniques that involve intramuscular injections of anesthetics. In this article, we review three different intramuscular injection procedures that can be used to treat headache pain. These procedures include occipital nerve blocks, cervical injections and trigger point injections.

\section{CASE PRESENTATIONS}

\section{Case One--Occipital Nerve Blocks}

A 43 year old male was presented to the emergency department for the evaluation and management of his headache of recent onset. The patient described intermittent shooting pains that seemed to originate from the right occipital area. This headache had been present for over a week and had not responded to over-the-counter medications. Palpation over the occipital area easily reproduced the pain. He denied any other associated symptoms and denied any other relevant past medical, social or surgical history. In the emergency department the injection of bupivacaine $0.5 \%$ and methylprednisolone sodium succinate $20 \mathrm{mg}$ with a 25 gauge needle $(1.5 \mathrm{~cm})$ into the muscles of the occipital skull brought immediate relief to the headache pain. This patient's clinical presentation was consistent with the diagnosis of occipital neuralgia.

\section{Case Two--Cervical Injections}

This 33 year-old woman was presented to the emergency department for pain relief from her usual migraine headache that began two days earlier. She described light sensitivity,

*Address correspondence to this author at the Department of Emergency Medicine, Medical College of Georgia, 1120 15th Street, Augusta, Georgia 30912, USA; Tel: 706-721-7144; Fax: (706)-364-2611;

E-mail: Imellick@mcg.edu nausea and vomiting. Her usual abortive medications were attempted without relief. The headache began on the left but became bilateral and was reported using a numeric descriptor scale as $10 / 10$ in severity. The patient denied any other medical problems. She was treated with injections of $1.5 \mathrm{~mL}$ of bupivacaine bilateral to the spinous process of the seventh cervical vertebrae. The patient experienced relief of her headache to $1 / 10$ in less than five minutes. She also described complete relief of her photophobia and nausea. Subsequently, the patient reported that she did not have her usual headache postdrome that typically would affect her during the following 24 hours.

Nine days later this patient returned to the emergency department for treatment of a migraine headache that was initiated by the "smell of strong cologne". Again, photophobia and nausea accompanied the headache. The patient again received bilateral intramuscular injections of $1.5 \mathrm{~mL}$ of $0.5 \%$ bupivacaine at the level of $\mathrm{C}-7$ spinous process. The time from the anesthetic injections to complete headache relief was exactly six minutes. The patient had two subsequent visits to the emergency department for similar migraine headaches over several months and responded consistently to the cervical injection therapy.

\section{Case Three--Trigger Point Injections}

A 24 year old was female presented for evaluation of headache pain that had been present for three days. Muscle tenderness was detected by palpation bilaterally over the anterior temporal area and several milliliters of bupivacaine $0.5 \%$ were used to inject these areas. The patient had rapid relief of her headache.

\section{DISCUSSION}

\section{Occipital Nerve Blocks}

With this procedure the greater and lesser occipital nerves are anesthetized. These nerves are commonly involved in patients suffering from cervicogenic headaches [5] and occipital neuralgia [6]. However, evidence exists to support the use of occipital nerve blocks for a much larger spectrum of primary headaches [7]. 
The greater occipital nerve arises from the $\mathrm{C} 2$ nerve root and after traveling deep in the paraspinal musculature becomes superficial just below the superior nuchal line and lateral to the occipital protuberance. The nerve travels just medial to the occipital artery at these locations. The lesser occipital nerve is the terminal branch of the superficial cervical plexus and becomes superficial over the inferior nuchal line. The greater occipital nerve block technique, first involves identifying the nerve at its point of entry to the scalp along the superior nuchal line midway between the mastoid process and occipital protuberance. (Fig. 1) The patient will report pain as the nerve is palpated along this distribution. The point of maximal tenderness should be identified and used as the injection site [8,9]. The nerve typically exits approximately $3 \mathrm{~cm}$ below and $1.5 \mathrm{~cm}$ lateral to the inion or bony prominence of the occipital skull. (Fig. 2) The scalp should be cleansed with alcohol or another appropriate antiseptic. Anesthetic agents commonly used include $2 \%$ lidocaine or $0.5 \%$ bupivacaine. A corticosteroid is often added to the anesthetic being injected. To reduce patient discomfort, the superficial skin can be anesthetized by creating a small wheal using a 27 -gauge needle with $1 \%$ or $2 \%$ lidocaine. Alternatively, a vapocoolant can also be used to reduce discomfort $[10,11]$. A 25 gauge needle is directed towards the occiput until bony resistance is felt. A small amount of anesthetic is injected at that location. The needle is then pulled back until it is just under the skin then redirected laterally and medially as the anesthetic is injected. (Fig. 3) As part of the process the paraspinal muscles near the suboccipital region are infiltrated with anesthetic. Since the smaller third occipital nerve exits medial to and in close proximity to the greater occipital nerve, it too is anesthetized. (Fig. 2) Once the syringe is completely withdrawn, the injected area should

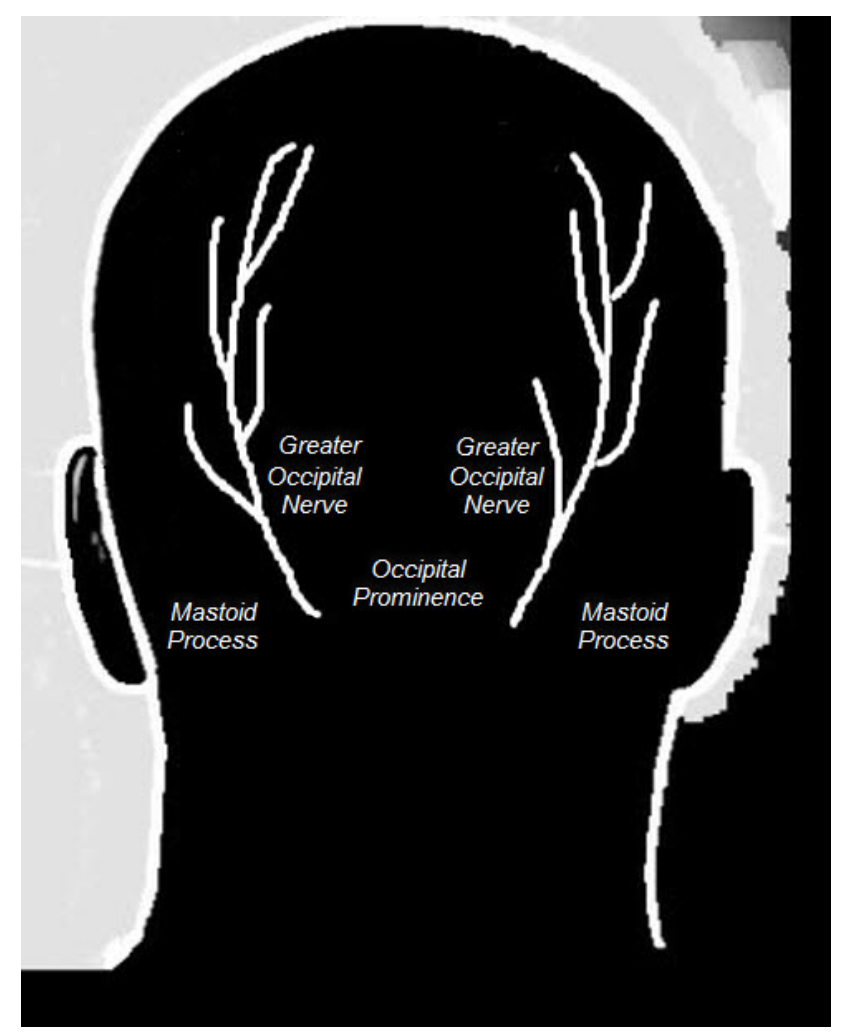

Fig. (1). Artistic rendition of the greater occipital nerves. be massaged and compressed to allow for better distribution of the anesthetic. An alternative technique consists of anesthetizing the nerve at a more distal site over the occipital ridge. The occipital artery is palpated one-third of the way from the inion to the mastoid process and the injections are made just medial to the occipital artery and then additional injections are made medial and lateral to this point [9]. Response rates have been reported to be about $85 \%$ [9]. Hypesthesia occurs within 1 to 2 minutes, extending upwards on the scalp to the interaural line. Overall, occipital nerve injections are safe but some adverse side effects such as dizziness, lightheadedness or local tenderness at the site of injection may occur. The use of local steroids has been associated with alopecia and hypopigmentation of the surrounding skin.

\section{Cervical Injections}

The bilateral lower cervical injections with bupivacaine is a recently reported technique for managing headache pain $[12,13]$. Additionally, this procedure also appears to provide some relief to patients with orofacial pain [14]. The mechanism is currently unknown, but based on the therapeutic response the authors suggest that the sensitized trigeminocervical complex is somehow calmed [15-18]. Previous work has established that cervical and trigeminal afferents as well as other structures with profound antinociceptive effects converge on the brainstem and are known to synapse with the trigeminocervical complex [19, 20].

Cervical injection is performed at the lower cervical or upper thoracic dorsal spine. The field is cleaned with antiseptic solution such as triclosan $0.25 \%$ (Chlorosept), betadine or alcohol swabs. Using a 25-gauge 1.5-inch needle, $1.5 \mathrm{ml}$ of $0.5 \%$ bupivacaine, 1 or $2 \%$ lidocaine are one's anesthetic options. The needle is inserted 1 to 1.5 inches into the paraspinal muscles, $2-3 \mathrm{~cm}$ bilaterally, at C6 or C7 cervical vertebrae $[12,21]$. (Fig. 4) The entire amount of anesthetic solution selected $(1.5 \mathrm{~mL})$ is deposited in each injection location. Always withdraw the plunger before injecting to ensure that needle is not in a blood vessel. The injected area can be massaged afterwards to facilitate anesthetic absorption and a band-aid can be placed over the injection sites. While the therapeutic response is typically rapid, it can take up to 20 minutes before the medication effect is noted. If patients do not report any pain relief, other therapeutic techniques should be tried $[12,21]$. Patients should be warned about injection site soreness which can last anywhere from 24 to 48 hours. Other potential minor complication of this procedure include, pain and irritation at the site of injection, vasovagal syncope, and hematoma formation. Patients should be informed of these potential risks before the procedure is performed. A video of the cervical injection procedure titled "Cervical Injections for Headaches" is available on YouTube ${ }^{\circledR}$ [22].

\section{Trigger Point Injections}

Myofascial trigger points have been postulated as an etiology for headaches [23-27] and trigger point injections have been described as successful in the management of these headaches [25-27]. Brofeldt and Panacek described the relief of headaches following the injection of anesthetic in the suboccipital and anterior temporal areas in their 1998 article [27]. Their technique is described as a two step procedure that involves identifying the proper injection site and then 


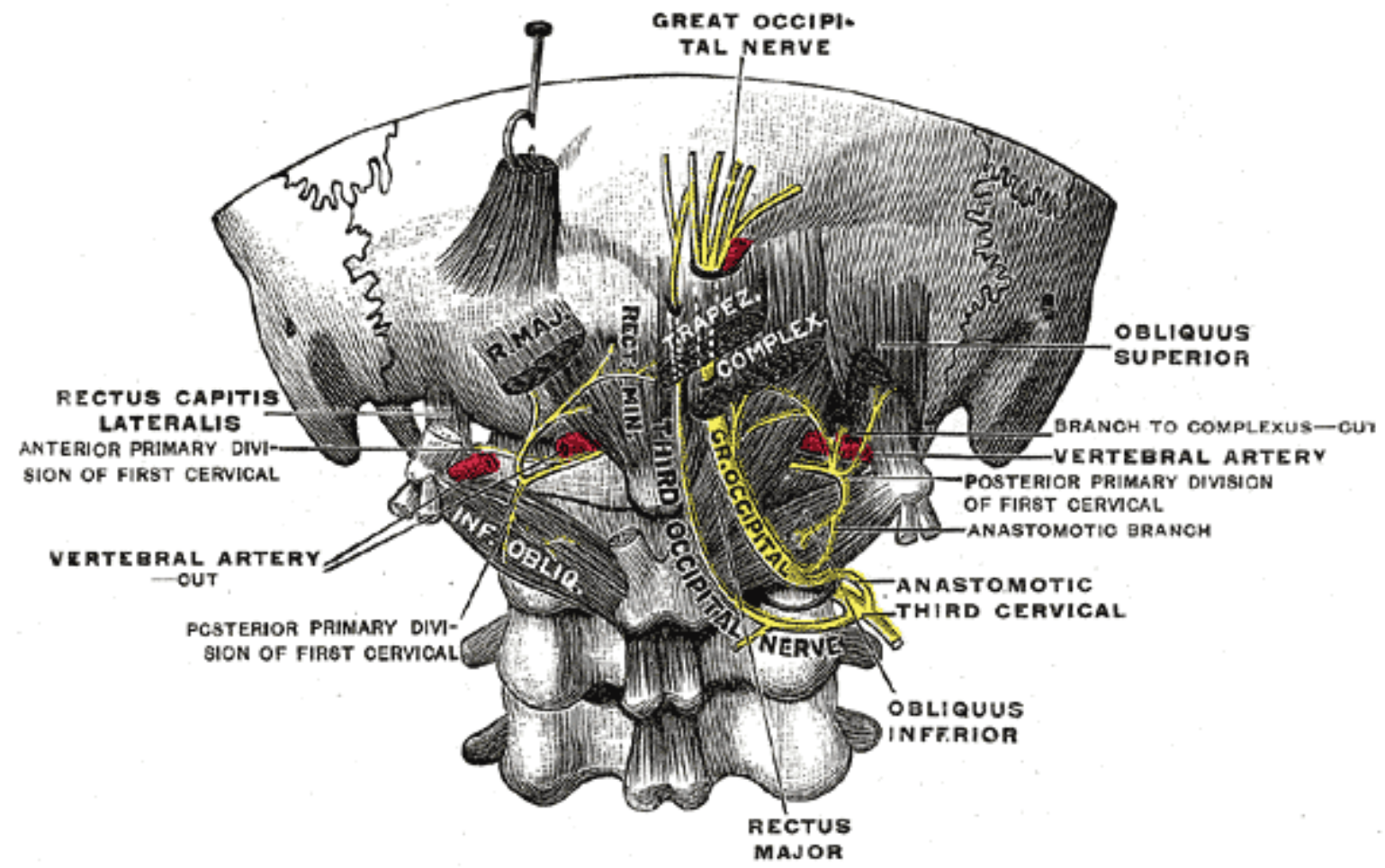

Fig. (2). Gray's Anatomy drawing of the great occipital nerve and base of skull. (Public Domain).



Fig. (3). Occipital nerve block.

administrating the injection. To identify the injection site, various sites on the patients head and neck are palpated with the tips of the index and middle fingers using firm circular pressure while paying close attention to the suboccipital and anterior temporal areas. Anterior pressure is applied to the general area where the greater occipital nerve penetrates the semispinalis capitis muscle located approximately two finger breaths inferior to the superior nuchal line and one to two finger breaths lateral to the occipital protuberance. For the anterior temporal area, pressure is applied to the slight depression just posterior to the lateral orbital rim and superior to the zygomatic arch. According to the authors, the appropriate site for injection is indentified when focal pressure reproduces or increases the patient's headache symptoms. The next step is the intramuscular injection for which a $50 / 50$ mixture of $2 \%$ lidocaine and $0.25 \%$ bupivacaine buff- ered with a $1 / 10$ volume of $8 \%$ sodium bicarbonate is used. A 27 -gauge needle on a $5 \mathrm{ml}$ syringe is inserted through the area of maximal tenderness until the needle makes contact with the cranium. To make contact with the inferior portion of the occiput bone, the needle is guided in a 45-60 degree angle superiorly. Once the needle is at the periosteum, continuous pressure is applied on the syringe and each focally tender area is "fanned" with $1-5 \mathrm{ml}$ of anesthetic solution by moving the needle in multiple directions, in and out of the tender area. Aspiration to avoid injection into a vessel is generally not recommended if the solution is injected simul-

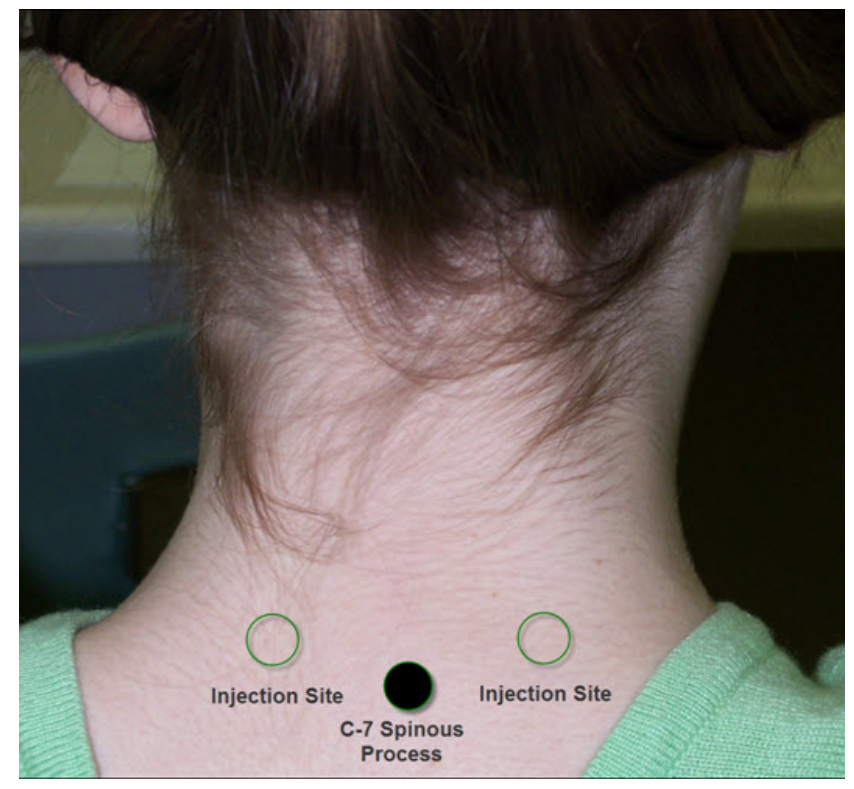

Fig. (4). Sites of needle insertion for the cervical injection technique. 
taneously during fanning of the needle. Once the syringe is withdrawn, the area of injection is massaged for at least 30 seconds. The injection is considered successful when focal palpation no longer reproduces the headache symptoms [27]. The authors reported that "two-thirds" of their patients had a therapeutic response.

In the report by Young et al. the combination of $8 \mathrm{~mL}$ of $0.05 \%$ bupivacaine mixed with $2 \%$ lidocaine is preferred for the injections [9]. Their technique involves identifying the injection sites by palpating for areas of tenderness in the paraspinal, suboccipital and trapezius muscles. A total of $0.5-1 \mathrm{~mL}$ are injected per site, with the dose divided between three triangularly oriented sites reached without removing the needle from under the skin [9]. When the trapezius muscle is injected near the apex of the lung, the authors pinch the muscle to isolate the muscle and decrease the chance of a pneumothorax. Steroids are often added to the anesthetic when trigger point injections are performed [9].

While the occipital injection location described by these authors is very likely an occipital nerve block and the described paraspinous injections may be similar to the lower cervical injections, the injection of the described trigger points, including temporal, and trapezius muscles, would appear to have some benefit.

\section{CONCLUSION}

In this article we described three different intramuscular anesthetic injections that have reported therapeutic benefit for managing headache pain. While there are multiple therapeutic modalities potentially applied to relieve headache pain, intramuscular anesthetic injections other than greater occipital nerve blocks are currently not widely utilized, recognized or researched. The clinical importance of cervical injections and trigger point injections remains to be further clarified.

\section{REFERENCES}

[1] Drotts DL, Vinson DR. Prochlorperazine induces akathisia in emergency patients. Ann Emerg Med 1999; 34: 469-75.

[2] Coppola M, Yealy DM, Leibold RA. Randomized, placebocontrolled evaluation of prochlorperazine versus metoclopramide for emergency department treatment of migraine headache. Ann Emerg Med 1995; 26: 541-6.

[3] Jones J, Sklar D, Dougherty J, White W. Randomized double-blind trial of intravenous prochlorperazine for the treatment of acute headache. JAMA 1989; 261: 1174-6.

[4] Ginder S, Oatman B, Pollack M. A prospective study of i.v. magnesium and i.v. prochlorperazine in the treatment of headaches. $\mathbf{J}$ Emerg Med 2000; 18: 311-5.

[5] Available from: http://ihs-classification.org/en/02_klassifikation/ 03_teil2/11.02.01_cranial.html

[6] Available from: http://ihs-classification.org/en/02_klassifikation/ 04_teil3/13.08.00_facialpain.html
[7] Tobin J, Flitman S. Occipital nerve blocks: when and what to inject? Headache 2009; 49(10): 1521-33.

[8] Caputi CA, Firetto V. Therapeutic blockade of greater occipital and supraorbital nerves in migraine patients. Headache 1997; 37(3): 174-9.

[9] Young WB, Marmura M, Ashkenazi A, Evans RW. Greater occipital nerve and other anesthetic injections for primary headache disorders. Headache 2008; 48: 1122-5.

[10] Reis EC, Holubkov R. Vapocoolant spray is equally effective as emla cream in reducing immunization pain in school-aged children. Pediatrics 1997; 100(6): e5.

[11] Hijazi R, Taylor D, Richardson J. Effect of topical alkane vapocoolant spray on pain with intravenous cannulation in patients in emergency departments: Randomised double blind placebo controlled trial. BMJ 2009; 338: b215.

[12] Mellick LB, McIlrath ST, Mellick GA. Treatment of headaches in the ED with lower cervical intramuscular bupivacaine injections: a 1 -year retrospective review of 417 patients. Headache 2006; 46(9): 1441-9.

[13] Mellick GA, Mellick LB. Lower cervical injections for headache relief. Lett Headache 2001; 41: 992-4.

[14] Mellick GA, Mellick LB. Regional head and face pain relief following lower cervical intramuscular anesthetic injection. Headache 2003; 43: 1111-3.

[15] Abrahams VC, Anstee G, Richmond FJ, Rose PK. Neck muscle and trigeminal input to the upper cervical cord and lower medulla of the cat. Can J Physiol Pharmacol 1979; 57: 642-51.

[16] Piovesan EJ, Kowacs PA, Tatsui CE, Lange MC, Ribas LC, Werneck LC. Referred pain after painful stimulation of the greater occipital nerve in humans: evidence of convergence of cervical afferences on trigeminal nuclei. Cephalalgia 2001; 21: 107-9.

[17] Bartsch T, Goadsby PJ. Stimulation of the greater occipital nerve induces increased central excitability of dural afferent input. Brain 2002; 125: 1496-509.

[18] Bartsch T, Goadsby PJ. Increased responses in trigeminocervical nociceptive neurons to cervical input after stimulation of the dura mater. Brain 2003; 126: 1801-13.

[19] Bartsch T, Goadsby PJ. The trigeminocervical complex and migraine: Current concepts and synthesis. Curr Pain Headache Rep 2003; 7: 371-6.

[20] Mason P. Deconstructing endogenous pain modulations. J Neurophysiol 2005; 94: 1659-63.

[21] Mellick LB, Mellick GA. Treatment of acute orofacial pain with lower cervical intramuscular bupivacaine injections: a 1-year retrospective review of 114 patients. J Orofac Pain 2008; 22(1): 57-64

[22] Available from: http://www.youtube.com/watch?v=oy $1 \operatorname{lgg} v x V 9 Y$

[23] Davidoff RA. Trigger points and myofascial pain: toward understanding how they affect headaches. Cephalalgia 1998; 18(7): 43648.

[24] Fernández-de-Las-Peñas C, Alonso-Blanco C, Cuadrado ML, Gerwin RD, Pareja JA. Myofascial trigger points and their relationship to headache clinical parameters in chronic tension-type headache. Headache 2006; 46(8): 1264-72.

[25] Venancio Rde A, Alencar FG Jr, Zamperini C. Botulinum toxin, lidocaine, and dry-needling injections in patients with myofascial pain and headaches. Cranio 2009; 27(1): 46-53.

[26] Harden RN, Cottrill J, Gagnon CM, et al. Botulinum toxin a in the treatment of chronic tension-type headache with cervical myofascial trigger points: a randomized, double-blind, placebo-controlled pilot study. Headache 2009; 49(5): 732-43.

[27] Brofeldt BT, Panacek EA. Pericranial injection of local anesthetics for the management of resistant headaches. Acad Emerg Med 1998; 5(12): 1224-9.

(C) Mellick and Verma; Licensee Bentham Open.

This is an open access article licensed under the terms of the Creative Commons Attribution Non-Commercial License (http://creativecommons.org/licenses/by-nc/3.0/) which permits unrestricted, non-commercial use, distribution and reproduction in any medium, provided the work is properly cited. 